\title{
É POSSÍVEL UMA POLÍTICA DELIBERATIVA PARA 0 TRABALHO?
}

\author{
Leonardo Mello e Silva
}

Este $\operatorname{artigo}^{1}$ pretende discutir a viabilidade de um enfoque baseado em alguns tópicos da literatura sobre democracia deliberativa, com o intuito de dar conta de algumas características das relações industriais dos últimos anos no Brasil, tendo em vista a dominância de um sindicalismo de tipo propositivo sobre um sindicalismo de tipo reivindicativo. Segundo aquele enfoque, a consecução de acordos democráticos, independente dos contextos societais em que se aplique, está condicionada ao preenchimento de algumas precondições, que se traduzem em requisitos necessários para a negociação, entre os quais os mais importantes são: 1) requisito de participação: que todas as partes interessadas participem, seja diretamente, seja indiretamente, da discussão e da decisão; 2) igualdade: que todas as partes participem numa base de relativa equivalência, ao menos quanto à possibilidade de propor soluções e saídas para os problemas apresentados, sem coerção ou constrangimento; 3 ) racionalidade: que todas as partes sejam capazes de apresentar seus

\footnotetext{
1 Versão ligeiramente modificada de texto apresentado originalmente no XXIX Encontro Anual da Anpocs, outubro de 2005.
} 
interesses e defendê-los sob uma ótica da universalização dos resultados; 4) justificação: que as partes sejam capazes de basear os seus interesses em argumentos.

Essas seriam exigências morais que, uma vez respeitadas, confeririam legitimidade à decisão saída do processo deliberativo. Concebida, em nível de grande generalidade, para a discussão de temas institucionais e de escolha pública, a política deliberativa será aqui deslocada para a esfera do trabalho, a fim de testar a pertinência de suas noções em situações mais restritas.

\section{Por que democracia deliberativa?}

A democracia deliberativa (DD) - ou, simplesmente, procedimento deliberativo - em geral aparece na literatura como uma alternativa à mera opção da escolha pelo voto como forma de resolver conflitos e organizar preferências. Discutir os problemas envolvidos na escolha confere maior legiti144 midade a essa última, isto é, à decisão tomada.

Outro argumento em favor da DD é que ela facilita a tomada de decisão, dada a complexidade das variáveis envolvidas no controle das conseqüências a partir da decisão mesma, o que, para decisores políticos, é um constrangimento bastante presente. Processos cooperativos de tomada de decisão, nesse sentido, são eficazes do ponto de vista do resultado. Não só porque eles potencializam a possibilidade de encontrar uma conseqüência oculta, a partir da decisão a ser tomada - e, portanto, de descobrir conexões até então escondidas, não previstas originalmente: "duas cabeças pensam melhor do que uma", "chance de ver outros ângulos da questão" etc. -, mas também porque reduzem as probabilidades de uma decisão com base em uma cadeia lógica de raciocínio que, no limite, foge completamente à plausibilidade concreta (uma racionalidade totalmente abstrata que, a partir de certo nível, deixa de ser razoável). Nessa última visão sobre a eficiência de uma decisão tomada com base em discussão coope- 
rativa, o corolário é que uma visão do poder como violência - imposição da vontade - deixa de ser pertinente. Assim, e inversamente, para aqueles que partilham de uma visão do poder enquanto violência, a DD abre as portas perigosamente para experiências de "perda de poder".

Um terceiro argumento em favor da DD é que o cidadão deve justificar o seu ato de escolha diante de outros cidadãos: ele tem de apresentar as razões de sua escolha, torná-la pública. Esse é o ponto de discórdia com relação a uma visão de escolha pública que concebe o resultado a partir de uma agregação de interesses que se expressa apenas e tão-somente na decisão: para essa última visão, o trabalho "reflexivo" é feito internamente ao próprio sujeito, sem necessidade de confrontá-lo com outros. Nesse sentido, o sujeito não pode nunca mudar de opinião antes do ato (por exemplo, o voto), ainda que possa fazê-lo depois.

Enfim, a justificação da escolha conduz à questão da necessidade de persuasão: demonstrar ao outro que o seu (do cidadão) é o melhor argumento. Discutir ao invés de simplesmente decidir (votar) reforça o grau de consenso ${ }^{2}$ acerca da questão a ser decidida, o que facilita ademais a sua implementação porque dissemina entre aqueles que tiveram o seu ponto de vista preterido com respeito ao ponto de vista da maioria a noção de que ao menos ele foi submetido a um debate, e que o ponto de vista vencedor representa, de fato, o melhor argumento. A percepção, entre os cidadãos, de que suas demandas foram objeto de uma apreciação equilibrada e justa (e não simplesmente submetidas a um tratamento do tipo "rolo compressor") é vital para reforçar a legitimação, perante os interessados, dos próprios procedimentos, e isso é muito importante para consolidar a prática deliberativa.

${ }^{2}$ Mesmo - ou talvez principalmente - que o consenso não esteja pressuposto no ponto de partida. 
O perigo desse tipo de prática é que ela pode levantar uma série de inconveniências não-pensadas relacionadas à decisão, uma virtude paradoxal derivada da própria discussão e de uma espécie de saturação do exercício de racionalidade investido nela: conseqüências não previstas afloram nesse caso, e quem estava a favor pode tornar-se contra, ou vice-versa. No entanto, ao se persistir nesse raciocínio, o círculo não tem fim, e as inconveniências de discutir ao invés de simples e resolutamente decidir parecem ser sempre menores do que maiores, isto é, os resultados em termos de legitimação e de consenso compensam largamente o efeito de a decisão não preencher inteiramente os interesses dos participantes tomados isoladamente. Ademais, uma visão extremamente anti-holística - como parece ser o caso para os advogados do "excesso de discussão" - obscurece nesse caso o fato da interação e da virtude social da própria discussão.

146 Relacionado a esse último ponto está a conseqüência política da discussão como encontro de deliberações privadas de pessoas racionais e, portanto, moralmente responsáveis. Nesse caso, a discussão possui vantagens não apenas pragmáticas, ao reforçar o consenso da comunidade diante de uma decisão, facilitando a sua implementação, mas sobretudo vantagens civis, ao contribuir para solidificar a identidade da própria comunidade. Discussão, que se desenrola no nível abstrato das idéias, e participação, que tem lugar no nível prático da ação, tornam-se assim quase equivalentes.

Em suma, apresentar justificativas para a decisão - tornando essa última uma "decisão informada", com implicação para a educação moral dos cidadãos - parece ser o elemento forte de uma política baseada na deliberação. Ela envolve, ademais de um desenvolvimento moral dos cidadãos, também uma experiência coletiva devida à formação pública da vontade, e que deriva da necessidade de persua- 
são mútua. Um tal exercício reflexivo, conquanto possa ser realizado na solidão da consciência, é menos rico de conseqüências do que quando realizado em conjunto, pois nesse caso podem-se comparar as razões e argumentos que cada um oferece para as soluções apontadas: por que alguém "ganhou" ou "perdeu"?; saber (aprender por meio) das razões apresentadas.

Um elemento escondido ou recalcado nas discussões sobre política deliberativa é o seu aspecto propriamente sociológico, forçosamente envolvido na decisão; qual seja, a desconstrução da pressuposição de "sujeitos livres" que emerge em uma situação ideal de discurso (a decisão deliberativa). Isso será abordado mais à frente. Outra reserva vem de abordagens do individualismo metodológico que, embora no campo da política deliberativa, apontam para o fato de que, uma vez que esteja em causa o bem comum, a deliberação não pode incidir sobre os fins, mas apenas sobre os meios que visam a atingir os fins. Outros, conforme já visto acima, concedem a possibilidade de a discussão, visando à deliberação, ter o poder de mudar as preferências iniciais dos atores, mesmo que se trate de crenças relacionadas ao bem comum.

As considerações até aqui feitas sobre DD tiveram o propósito de introduzir a discussão sobre a possibilidade de aplicação de seus princípios na esfera das relações de trabalho.

\section{Incidência de políticas deliberativas}

Nessa altura, uma precisão faz-se necessária. No campo das relações de trabalho, o percurso histórico das lutas de classe tem apontado para a conversão de assuntos privados (assuntos relacionados ao direito do proprietário da força de trabalho em dispor de sua mercadoria sem a interferência de qualquer constrangimento definido externamente ao ato de compra e venda) em questões públicas, estando ele associado a uma ampliação do âmbito da justiça 
(por exemplo: justiça do trabalho). A politização do privado - de uma das camadas ou dimensões de que faz parte a esfera privada - participa de uma trajetória progressista no sentido de trazer para a política um conjunto de problemas que não eram então sequer tematizados.

Entender as variações do significado da esfera privada, suas camadas ou dimensões, é importante para esclarecer o que está envolvido nas transformações do trabalho. Essas variações ou camadas dizem respeito não apenas à propriedade, mas também à privatividade, à interioridade, à intimidade, ao doméstico e ao sagrado, segundo a caracterização proposta por Hannah Arendt ${ }^{3}$. Assim, se o movimento de publicização do privado correspondeu a uma ampliação da justiça pela redefinição dos limites do que seja uma questão "moral" (uma questão, em última instância, ligada aos fins, sobre a qual a discussão pública não podia se pronunciar), ele não elimina aquelas outras dimensões da esfera privada 148 que estão associadas ao que foi designado aqui por "privatividade" e seus correlatos. Mesmo que essa última esteja desigualmente disponível segundo uma determinada (histórica) divisão social do trabalho, nunca chegou a ser completamente eliminada. Ademais, os significados das noções de "intimidade" e "interioridade" são constantemente redefinidos pelas classes sociais. Desse modo, no século XIX, em situações como aquelas descritas por Engels para a classe trabalhadora da Inglaterra, o espaço privado dos trabalhadores viu-se encurtado em relação à medida burguesa para a divisão do trabalho na sociedade e na família. Mas isso não significou absolutamente a inexistência de "intimidade" ou "interioridade" entre os operários ingleses, senão que essas noções só fazem sentido na perspectiva de uma cultura e de uma forma de expressão próprias, às vezes irreconhecíveis para a definição dominante e convencional.

\footnotetext{
${ }^{3}$ Arendt, 1991, pp. 68-78.
} 
Hoje, o que se observa é que a esfera relativamente protegida da intimidade acaba sendo tematizada à outrance porque os novos modelos de gestão incitam uma exposição permanente, por parte de seus subordinados, dos recursos originários da família, das relações de amizade e dos sentimentos. Assuntos relativos à moral privada ou ética particular, os quais deveriam ser contidos pela barreira do diálogo circunscrito por valores e normas razoáveis passíveis de acordo (conformando uma "moral pública"), ganham foros de legitimidade, ao menos no mundo da produção. A neutralidade quanto às "concepções do bem" é subvertida, em alguma medida, pela iniciativa das estratégias pós-fordistas de organização, que exige a publicização do lado "oculto" da personalidade e do envolvimento cognitivo e emocional do executante do trabalho.

O discurso da lean-production ${ }^{4}$, na atualidade, é pródigo nesse gênero de artifícios. O movimento, contudo, é o inverso daquele observado no percurso histórico mencionado acima, isto é, o de publicização do privado. Nesse último caso, os limites da neutralidade quanto à "concepção do bem" foram transpostos pelo movimento social (em especial o movimento operário), que trouxe para a esfera pública assuntos então recobertos por um estatuto de verdade moral (o caráter indiscutível da propriedade no contexto da economia mercantil e sua distância em relação aos assuntos da cidade), constituindo-os em assuntos públicos. Dessa forma, aqueles assuntos deixaram de ser não-formuláveis; ao contrário, passaram a admitir a possibilidade de serem postos em questão. Uma tal precisão é útil, em ter-

\footnotetext{
${ }^{4}$ Trata-se da "produção enxuta", a qual foi disseminada no mundo industrial do Ocidente como uma adaptação dos princípios do toyotismo, a partir do início dos anos 1990. A obra de referência é Womack et al. (1990). Muitos são os exemplos que se poderia mobilizar para demonstrar a utilização da esfera doméstica e da família como componente do produtivismo fabril. Esses exemplos estão em boa parte na literatura da sociologia do trabalho que se debruçou sobre tais modelos.
} 
mos analíticos, porque expõe o deslocamento semântico sofrido historicamente pelo par "questões privadas" e "questões públicas", denunciando o caráter dinâmico dessas definições. É também o que traz o interesse para a atualidade, pois a incidência de uma política deliberativa depende, de certo modo, de uma circunscrição dos âmbitos da justiça e da moral, da política e da "boa vida".

A partir desse ponto, pode-se perceber o seguinte: duas concepções de diálogo estão em disputa. A primeira (liberal) restringe o raio de assuntos ou temas que podem ser objeto de deliberação pública, se e quando incidam sobre questões acerca da "boa vida" (ou dos "fins últimos", ou ainda: de "éticas particulares"); a segunda (radical) admite a possibilidade de transformação dos próprios "fins". A primeira não admite a mistura entre temas de justiça e de éticas particulares (ou valores morais particulares), dado o fato do pluralismo; a segunda, ao contrário, parte da expectativa de que aqueles 150 valores ou éticas - em última instância, "preferências" definidas individualmente $a$ priori - não são desde sempre fixos e podem eventualmente mudar. Legalidade e moralidade (entendida no sentido privado, e não público), como dois princípios antinômicos, recobrem respectivamente os pares do "justo" e do "bem", do público e do privado. Não há, nessa primeira concepção, lugar para a tematização de novos direitos, uma vez que a democracia é entendida como forma cuja capacidade se mede pela força de garantir o fato do pluralismo. Alternativamente, a criação de novos direitos ocorre por meio de lutas pelo poder de estabelecer uma nova definição do que se entende por "público", "privado", "bem", "moral", assim como os seus limites. Inibir tais lutas, contudo, seria uma decorrência lógica de manter a discussão e o diálogo confinados à defesa da norma básica (por exemplo, a Constituição) que assegura o direito de todos à voz, igualmente e independente de formas (in)visíveis de opressão, que podem não aparecer em uma formulação discursiva. 
Ora, dada a diferença entre aquelas duas modalidades possíveis de discussão ou de diálogo, sabemos que a primeira (liberal) foi desafiada pela emergência de movimentos sociais que alargaram o âmbito da política. O que sucede na nova configuração produtiva, que tem na difusão da lean production sua expressão mais modelar, é que a esfera privada é desafiada contemporaneamente pela indiscrição da empresa, em seu formato de gestão e mobilização da força de trabalho, deixando pouco à vontade o discurso autolimitador do liberalismo quanto à partição clássica entre assuntos de moral pública e privada. Há uma discussão invasiva de temas ligados à privacy ${ }^{5} \mathrm{e}$ ao mesmo tempo uma inibição do diálogo de temas associados à esfera pública. O temor liberal de um ataque à privacidade, que está na origem da justificação do direito, deixa de ter efetividade nesses casos.

Dois outros aspectos devem ser ressaltados para compor o quadro extraído das práticas produtivas do presente. $\mathrm{O}$ primeiro é a margem de autonomia e responsabilidade na execução de algumas tarefas do processo de trabalho que, contrariamente aos preceitos tayloristas, passam a ser incorporados em algumas funções de produção e em atividades de serviços. Mas as margens de escolha, quando a ocasião permite, costumam ser muito estreitas, sem oportunidade de uma real participação nas decisões estratégicas da firma. O segundo - e fortemente relacionado ao primeiro - é a especialização técnica que afeta também o discurso: o grau de expertise solicitada para participar de negociações coletivas ou no âmbito das empresas afasta muitos pretendentes de uma tematização aberta de problemas que, no entanto, são sentidos e experimentados subjetivamente, sem encontrar uma expressão pública. A delegação da vontade para representantes eleitos (representante sindical, comissão de fábrica) pode mitigar o problema mas não o resolve

\footnotetext{
${ }^{5}$ Veja-se as notas 3 e 4, supra.
} 
definitivamente, pois o grau de especialização dos debates requerido (investimento, contabilidade, cenários prospectivos, correlação de variáveis econômicas cada vez mais globais) não acompanha o ritmo de formação - e, portanto, também da formação da vontade - do pessoal assalariado. Ademais, o handicap não é apenas conteudístico, mas também social, isto é, comportamento, jogo de corpo e virtudes expressivas entram igualmente em linha de conta na hora de pressupor condições de igualdade na argumentação. Isso reduz em muito as possibilidades de cobrar a efetiva realização das promessas saídas do processo de acordo e diálogo, pois muitas vezes a parte menos treinada ou socializada nos assuntos especializados não dispõe de recursos para saber se a contrapartida prática oferecida pela outra parte foi de fato "máxima" ou se, ao contrário, ela não estaria "escondendo o jogo". Nesse caso, pode-se esperar um fraco grau de accountability em relação às decisões tomadas, a despei152 to de elas terem se submetido à exigência de publicidade. Esses seriam alguns limites para um procedimento deliberativo, os quais podem ser encontrados de maneira típica em muitas ocasiões na esfera do trabalho, quer nas relações coletivas entre patrões e empregados, quer na organização do trabalho na empresa, na multiplicação de grupos de discussão, círculos de qualidade, times de produção, células e outros. Um olhar mais detido sobre iniciativas desse último tipo está reservado à seção que segue.

\section{Cooperação, negociação e deliberação}

Sistemas de trabalho dependentes em alto grau de flexibilidade não podem prescindir, ao menos idealmente, de arranjos cooperativos com a força de trabalho. O que seria uma exigência meramente organizacional apóia-se, na verdade, em exigências técnicas (a excessiva rigidez do sistema maquínico-mecânico impede uma reconversão rápida visando às demandas de novos produtos) e econômicas 
(concorrência baseada em diferenciação e qualidade), o que fornece um argumento de peso à necessidade de uma postura mais cooperativa no interior das relações de trabalho em sua generalidade, isto é, tanto nas atividades de serviço (elas mesmas, devido à natureza reflexiva da atividade, já mais facilmente susceptíveis a posturas gerenciais dispostas a "ouvir a voz" dos empregados), quanto naquelas tipicamente manufatureiras. Desse ponto de vista, a novidade de sistemas de gestão do trabalho mais compreensivos estaria muito mais entre essas últimas do que entre as primeiras.

Se a conexão entre cooperação e produtividade não é trivial, por outro lado, a dinâmica das relações de trabalho e das relações de classe, em sentido também institucional, não obedece a nenhuma correspondência automática com a temporalidade do mercado e da empresa. Ela tem uma temporalidade própria. Isso quer dizer simplesmente que sistemas de trabalho de empresas que se apresentam como cooperativos nem sempre correspondem a uma efetiva experiência de envolvimento por parte de sua força de trabalho. No entanto, é verdade que firmas que adotam uma postura organizacional mais conforme aos paradigmas dos novos modelos produtivos (pós-fordistas) estariam, em tese, mais próximas de uma inclinação negocial e, por conseguinte, a estabelecer relações de cooperação e de comunicação, ao invés de uma oposição sistemática e predatória entre capital e trabalho.

Nesse ponto, a introdução de uma prática deliberativa no mundo da produção causa uma certa fricção. É que enquanto a cooperação produtiva ressente-se negativamente de conflitos continuados para o bom desenrolar dessa esfera (avaliada, como se sabe, pelos critérios de eficiência), a multiplicação de embates baseados em pontos de vista diversos é um elemento enriquecedor da prática deliberativa quando aplicada às "cidades", isto é, à esfera da política (entendida menos em seu formato institucional e mais em 
sua acepção ampla como espaço público). Tanto mais uma prática negocial faz apelo à discussão permanente, menos ela conjura o conflito, alimento daquela prática; ao contrário, na vida da empresa, a discussão e as iniciativas cooperativas visam primordialmente a conter o conflito nos limites em que ele não bloqueie o fluxo funcionalmente produtivo da mesma. "Fazer emergir o conflito" só pode fazer sentido, do ponto de vista da empresa, como um procedimento tecnicamente justificado, visando a um controle preventivo de rupturas latentes, ao passo que na vida civil ele é condição para a oxigenação do sistema político. Desse modo, as relações de trabalho, pelo menos no âmbito dos processos de trabalho, estariam irremediavelmente presas a uma lógica decisionista, e não deliberativa. Já no âmbito das relações industriais, ao contrário, a coisa se passa diferentemente: as lutas de classe interferem, sim, na esfera do social e do político $\left(\right.$ cidadania social $\left.^{6}\right)$, ainda que tenham sua raiz em lutas 154 corporativistas. Mesmo nesse último âmbito, contudo, os conflitos não podem ser duradouros, sob pena de paralisar igualmente o sistema econômico. Mas é mais fácil tematizar aí problemas sob a inspiração dos valores e procedimentos deliberativos do que no âmbito privado da relação entre empresa e trabalhadores.

Qualquer abordagem não-reducionista do trabalho, seja ela institucionalista ou marxista, reconhece as conexões estreitas entre organização do trabalho e relações industriais, de tal maneira que mudanças em um pólo necessariamente rebatem no outro. Essas conexões são, em primeiro lugar, econômicas. Mas podem também enxertar práticas políticas que, em alguma medida, contaminam a economia, assim como o contrário também ocorre. Assim, as negociações coletivas, embora estejam presas a imperativos sistêmi-

${ }^{6}$ Como mostra Castel (1995), a trajetória do salariato modifica a própria natureza do liberalismo. 
cos, mas sendo também mais permeáveis a procedimentos deliberativos do que as negociações de empresa, podem ter influências sobre essas últimas. Quanto às implicações econômicas e sociais, não é difícil estabelecer a relação recíproca entre os dois âmbitos: basta lembrar que mudanças na classificação das ocupações (com conseqüências, por exemplo, nos níveis salariais), nos critérios de demissão ou de ascensão profissional, no tempo agregado de trabalho (jornada de trabalho do conjunto assalariado ou de determinado ramo de atividade), entre outros, têm imediato impacto no trabalho direto. Correlativamente, quando sérios rearranjos têm lugar na forma de se trabalhar (modos operatórios), é legítimo esperar uma recomposição nos tópicos consagrados da negociação coletiva (salário, emprego, qualificação, jornada etc.). O debate sobre a flexibilidade, como se sabe, está ligado exatamente a isso.

Pretende-se que, em um formato de contratação coletiva do trabalho, tal como pensado para as relações trabalhistas no Brasil no presente, o vértice possa estabelecer parâmetros que regulem o espaço antes indeterminado - salvo a interferência sindical, quando havia - da relação entre o patrão e o empregado na empresa. Ao sindicato seria deixada alguma margem de inovação bipartite, dentro, porém, de certos patamares de direitos mínimos elementares e "inegociáveis". A margem de inovação seria exatamente o momento em que uma negociação do conflito (pressupõe-se que a situação de classe é potencialmente sempre conflitual) teria lugar, atores coletivos aparecendo como sujeitos políticos com diferenças de pontos-de-vista em busca de uma entente. Pretende-se igualmente que experiências bem-sucedidas de concertação no âmbito das relações industriais possam funcionar como facilitadoras da expressão e da palavra, ali, onde vigoram apenas os critérios de produtividade e rentabilidade.

É bom lembrar que um tal esquema analítico, que faz um recorte muito rígido entre duas formas de racionalida- 
de das quais derivariam tipos de ação social, também eles orientados por lógicas muito bem definidas, tem uma certa dificuldade em lidar com fatos históricos que sugerem, ao contrário, uma indiferenciação de motivos práticos para pôr em marcha as reivindicações de grupos operários, embora os móveis iniciais delas possam ter sido bem específicos: quando se lutou contra a exploração do trabalho da mulher e do menor (abstraindo-se os apelos emancipatórios que podiam então estar presentes nessas reivindicações), esse não foi apenas um esforço direcionado para o enquadramento da força de trabalho industrial, mas também por justiça. Fazer a distinção a posteriori entre os móveis de justiça e aqueles ligados ao mercado de trabalho é possível mas talvez fosse mais interessante procurar o seu entrelaçamento no momento (histórico) em que foram formulados. O mesmo valeria para a diminuição da jornada de trabalho ou dos acidentes de trabalho. Mesmo em situação (posterior) de emergência do Estado de Bem-Estar Social, a mediação instrumental das reivindicações do trabalho crescentemente organizado e integrado não parece ter exaurido completamente a fonte de reivindicações que resvalam para tópicos de uma "vida boa" (privada) e moralmente (política) aceitável: as reivindicações de autonomia e de um trabalho significativo vieram em boa parte não de fora, mas de dentro do mundo industrial. Nada vaticina que, com os novos problemas ligados aos novos modelos produtivos, também ali não surjam novas frentes de batalha por justiça (lutas contra a exploração da insegurança, contra stress e a humilhação moral nos locais de trabalho reestruturados, por exemplo).

\section{Cooperação e economia da informação}

Tendo em vista a estreita correlação que tem sido apontada entre cooperação e produtividade, é oportuno mencionar um tratamento possível do quesito "confiança", quando este é traduzido por grau de acesso à informação recíproca entre 
as partes. Por outro lado, a confiança é básica para o estabelecimento de acordos deliberativos: deve-se supor todo o tempo que os agentes envolvidos em processos de discussão estão comprometidos com a veracidade de suas asserções. Nas relações de trabalho, tal quesito é muito importante: tanto maior o grau de desconfiança entre patrões e empregados, ou entre gerentes e subordinados, maiores as chances de um comportamento defensivo de parte a parte e, por conseguinte, de retenção de informação, às vezes relevante para solucionar um gargalo ou combater uma "deseconomia" devida a um arranjo defeituoso do processo, o qual pode ser de conhecimento dos agentes, mas oculto dos organizadores. Inversamente, a direção da empresa pode esconder decisões que afetam diretamente a sua força-detrabalho (como planos de enxugamento de pessoal ou introdução de novas máquinas, ambas com implicações no nível de emprego). Nos dois casos, é uma relação de confiança que é quebrada, e isso contamina negativamente a cooperação entre "os de baixo" e "os de cima". Por outro lado, a contrapartida desse tipo de comportamento é a transferência total da responsabilidade acerca do andamento do processo produtivo dos operadores diretos para a gerência e a supervisão, que prescrevem e aplicam normas do estilo the one best way.

Esquemas analíticos inspirados na teoria dos jogos levam a sério situações desse tipo, simulando modelos que jogam com as variáveis de incentivo ou desincentivo à cooperação e, portanto, ao compartilhamento da informação. No entanto, o processamento significativo dos agentes envolvidos nos processos de troca simbólica capta antes de tudo o juízo moral, ao invés de um cálculo racional. É um deficit de reciprocidade que aparece (em geral oriundo do lado mais fraco, isto é, daquele com menores recursos de poder), por exemplo, quando falha o circuito de crença na boa-fé do outro: as queixas são em geral relacionadas 
à "injustiça" da retribuição, com base, evidentemente, em alguma medida não-declarada, mas suposta de valor. É a costureira que reclama da encarregada porque ela não segue os critérios de eficiência (objetivos, válidos para todos), mas de amizade com a colega (critérios subjetivos); assim como o gerente que cobra mais empenho porque ficou do lado das operárias contra as invectivas do chefe... os exemplos poderiam ser multiplicados. Num outro registro, segurar informação é uma forma de luta em torno do poder de controlar o próprio trabalho, ao passo que, quando o saber associado a esse controle é apropriado pelo adversário, é o poder que é transferido.

O que é relevante notar na idéia de um padrão desejado de cooperação nas relações de trabalho é que ele não combina, ao menos em termos ideais, com um desenho contratualista nas relações industriais; esse último tende a privar de conteúdo a relação de confiança entre patrão 158 ou gerente e trabalhadores - esta é a sua forma adequada-, enrijecendo o canal de comunicação entre as partes - este é seu resultado prático. Assim, para sistemas flexíveis de produção, hoje, uma contratualização excessiva seria disfuncional. No entanto, um olhar retrospectivo da história social mostra (no Brasil, com certeza; nos outros países, com toda a probabilidade) um repertório de lutas pela contratualização, capitaneado pelo movimento operário; lutas essas que buscavam alargar, como se viu acima, a noção de justiça, usando os meios disponíveis do direito. A contratualização parece ser condição para um arranjo cooperativo mais favorável à parte mais fraca nas relações internas à empresa, assim como no passado. Afinal, a situação do mercado de trabalho é inseparável das condições de barganha entre as partes conflitantes em torno de saber e poder da produção.

Atualmente, a equação entre cooperação, flexibilidade e reestruturação do ambiente industrial coloca em um 
mesmo lado: 1) uma relativa permanência em termos de demanda de produtos; 2) contratos exercendo constrangimento entre aqueles que se encontram sob sua órbita, tanto do ponto de vista temporal quanto do ponto de vista das esferas de cobertura; e 3) pouco incentivo ao compartilhamento de informações e à cooperação produtiva. Nesse último caso, o dilema típico do tipo "quem sai na frente, se expõe mais”, próprio de um cenário que alimenta expectativas divergentes, pode travar as iniciativas de diálogo e discussão. Do outro lado da equação, incertezas do mercado seriam indutoras de um comportamento mais propenso à colaboração: contratos de âmbito menos abrangente reduzem os efeitos de desperdício associados a "bancar" situações muito distantes da realidade específica do ramo ou empresa, por um lado, enquanto, por outro lado, aumenta a dependência do trabalhador, que precisa do emprego, e reduz os estratagemas de práticas de controle e restrição da produção.

Mas além desse cenário da "cooperação pelo medo", haveria também espaço para consensos entre capital e trabalho baseados em alta qualificação, iniciativa e - eventualmente - participação na propriedade das firmas, reduzindo a dependência em relação ao mercado de trabalho: um maior poder deliberativo, nesse caso, seria uma decorrência quase direta da cooperação. Nessa última situação, o importante é que a cooperação via comunicação passa a contar como condição necessária para o desbloqueamento de informações e sua circulação pelo ambiente produtivo ${ }^{7}$.

\footnotetext{
${ }^{7}$ Essa observação é atestada por muitos autores (veja adiante nota 15 para um autor em particular). Piore (1995) menciona a necessidade de uma interação direta (pp. 99-100) entre indivíduos e organizações com vistas a um bom resultado em termos de inovação nos processos produtivos, ao invés de um formato baseado exclusivamente na competição de mercado. Ele aponta as vantagens de uma organização no formato de rede (networked organization), a qual seria dificilmente compatível com aquele último modelo ou "forma social".
} 


\section{Sindicalismo "negocial" e procedimentos deliberativos}

No Brasil, podem-se identificar, nos últimos anos, experimentos no âmbito político mais geral que tentam perseguir procedimentos deliberativos. Esses experimentos, claro, têm rebatimento nas relações de trabalho. Sindicatos, centrais, associações profissionais, federações de empresários, por exemplo, são atores coletivos com presença obrigatória em tais fora, por causa de sua expressão social. Pode-se mesmo sugerir a hipótese de que tais experimentos tiveram seu ponto de partida, no mundo do trabalho, precisamente com a détente representada pelas câmaras setoriais, na primeira metade dos anos $1990^{8}$. Inclui-se entre aqueles experimentos, nos últimos anos, a instalação do Conselho de Desenvolvimento Econômico e Social (CDES), no início do Governo Lula (2003). A inspiração em casos exemplares de concertação social levados a efeito em países da Europa continental é explícito. Nos consideranda do CDES, menciona-se a idéia-mestra de um "novo contrato social" como que a dar coerência a um movimento que se desdobra também em outras iniciativas: Mesa Nacional de Negociação Permanente (entre funcionários públicos e Governo), Fórum Nacional do Trabalho (FNT), entre outros. Em todos eles, a expectativa do legislador (entendido aqui não na acepção burocrática do Poder Legislativo mas no sentido político do "deliberador") é de que, nesses espaços de negociação, as demandas da sociedade civil possam ser filtradas antes da tomada de decisões. Uma justificativa adicional para a virtude da concertação, no caso brasileiro, é que ela contraria traços persistentes da cultura política predominante, a saber, a tradição de conciliação "por cima”, por um lado, e o legalismo ${ }^{9}$ excessivo (expresso,

\footnotetext{
${ }^{8}$ Há muita literatura sobre o assunto e seria desnecessário arrolá-la aqui. Consulte-se o texto-marco sobre esses estudos: Oliveira et al. (1993).

${ }^{9}$ O que é descrito pelo termo alemão Verrechtlichung. Trata-se de uma das acepções possíveis para a "formalização".
} 
por exemplo, no sistema corporativo de relações de trabalho), por outro.

As iniciativas de concertação, contudo, têm como característica central o fato de serem uma iniciativa do Poder Público, enquanto a contratação social ocorre entre agentes coletivos formalmente privados. Por isso, a experiência das câmaras setoriais havia sido, de certa maneira, um marco nas relações entre Estado e sociedade, e nas relações de trabalho em particular. Sua armação política (não propriamente institucional) traduzia-se no fato de que o "interesse geral" (limitado, que seja, a uma realidade de setores econômicos precisos) não era definido de cima para baixo, mas construído por meio de "contratos" que tinham a virtualidade de espalhar-se por toda a sociedade, sendo a capacidade de disseminação ou enxameamento diretamente proporcional à importância econômica do referido contrato -, daí o significado do "Acordo das Montadoras", com seu importante peso no interior da sociedade civil (incluída aqui, aliás, em sua acepção também de "sistema de necessidades"). A lembrança é oportuna porque, ontem como hoje, toda a vez que está em curso um processo de negociação do tipo "contratual", surge a objeção polêmica de que ele estaria se chocando contra uma instituição política já existente e dedicada ao propósito de dirimir conflitos os quais aquelas negociações elegem exatamente como objeto de tratamento. Foi assim com as câmaras, que pareciam sobrepor-se às negociações coletivas tradicionais, tanto quanto com o que ocorre hoje com o FNT e demais fora que congregam representantes de capital e trabalho, o mesmo valendo para o CDES, contra o qual foi levantado o conflito de competências com o Parlamento. Em todas as oportunidades, parece refletir-se a disjunção teórica entre a defesa da Constituição e do direito, por um lado, e a inclusão de temas de moral e justiça, por outro lado. A democracia deliberativa oscila entre conferir um papel predominante ao primeiro termo, 
enxergando o direito como guardião das normas básicas (sobre as quais nenhum dos participantes deve, na falta de convincentes razões, divergir) e da própria possibilidade de acordo, qualquer que ele seja; ou ao segundo termo, quando os contratos ou acordos ousam incluir temas que seriam forçosamente motivo de discórdia, pois remetem, em última instância, às éticas particulares. Num caso, a "moral pública" é entendida do ponto de vista formal, como a defesa do procedimento em si; no outro ela se aproxima de conteúdos substantivos que podem resvalar para definições parciais da "boa vida", o que seria perigoso do ponto de vista do pluralismo. A justificativa para a primeira posição é que, ao colocar o princípio político (moral) em primeiro lugar, a democracia deliberativa funciona como um anteparo à reivindicação de interesses próprios ou preferências particularistas (os agentes devem justificar racionalmente suas escolhas de um ponto de vista universalista), enquanto a segun162 da posição não exige que as reivindicações dos agentes apareçam primeiramente como "morais", senão como justas, isto é, enfatizam antes de tudo o aspecto da igualdade antes da deliberação. Vê-se que a alternativa é mais nuançada do que simplesmente aquela entre discutir ou decidir, ou seja, entre submeter os argumentos a uma reflexão pública ou fazê-la internamente à consciência individual, para só então emitir um juízo na vida pública. Ela envolve, na verdade, um entendimento do gênero de racionalidade que é mobilizada na deliberação, o que foge aos propósitos limitados desta comunicação.

Se os indícios de um movimento de contratualidade observados vêm do Estado para a sociedade (iniciativas de tripartismo baseadas na noção de concertação social), o mais interessante seria verificar o movimento oposto. No mundo do trabalho, acordos bipartite entre empregados e patrões podem ocorrer seja por mediação sindical, seja ainda de forma "espontânea" entre coletivos de trabalhadores 
e direção da empresa. Em quaisquer dos dois casos, o dado fundamental é a organização do fator trabalho como uma construção política, na medida em que nega o automatismo do mercado. Isso está de acordo com o sentido geral da contratação coletiva em nível nacional, que é o de regular o uso mercantil do trabalho, desde o nível intermediário (ramo de atividade) até o nível micro (empresa), tendo como pressuposto aquele dado fundamental mencionado acima. Dificilmente pode-se acreditar que, pelo mero fato de sua aplicação, as exigências mínimas para o procedimento deliberativo (participação, igualdade, racionalidade, justificação) não tenham nenhum efeito sobre a definição mesma do "bem". Esse efeito dinâmico está na própria raiz da criação de novos direitos, como se viu na discussão anterior. É nesse sentido que a publicização de interesses, tanto nos contratos bi quanto tripartites converte demandas da chave social, em que elas se encontram originariamente, para a chave da política.

\section{Testando os princípios da democracia deliberativa}

Nesta seção serão repassados muito dos argumentos já discutidos nas seções anteriores. Primeiramente, esboçamse alguns traços gerais dos acordos que desembocam em decisões mais ou menos pactadas, à guisa de $\operatorname{contratos}^{10}$. Em seguida - mas no momento mesmo de apresentação daqueles traços -, alguns casos específicos, típicos das relações entre o capital e o trabalho, "testarão" a hipótese do procedimento deliberativo. A idéia segue o tom geral do texto, ou seja, discutir a pertinência daquele procedimento num

\footnotetext{
${ }^{10}$ A terminologia não é neutra porque, no debate político-doutrinário que anima o mundo do trabalho organizado no Brasil atualmente, o sindicalismo contratualista é usado pelos seus adversários como sinônimo de um sindicalismo que privilegia os acordos em detrimento da luta intransigente na base. Por outro lado, viu-se anteriormente que o "contrato" pode conter duas significações até certo ponto opostas: a de "formalização", em primeiro lugar, e também a de acordos de baixo para cima atuando contra o legalismo (e o corporativismo).
} 
campo que as "relações industriais" consagraram como o domínio privilegiado da racionalidade instrumental.

Um dos aspectos que estão envolvidos nos acordos deliberativos é sua vocação de generalização: eles devem possuir como pressuposto a possibilidade de universalização; não podem, por conseguinte, ter uma aplicação condicionada; isso em termos de procedimento, porque em termos de conteúdo, a restrição é não só possível como realista: nos contratos micro, o âmbito de cobertura e de vigência é limitado, muito raramente se estendendo a toda a categoria e muito menos à classe. No entanto, o fato de ser estabelecido um acordo ou contrato depõe a favor de sua viabilidade em outras situações, como possibilidade formal: nenhuma razão interna poderia impedi-lo. Em termos concretos, é o que ocorre com o efeito-demonstração: um acordo de sucesso em uma área (ramo de atividade, setor, localidade, empresa) enseja sua reprodução alhures. Mesmo que se trate de um acordo "corporativo" (isto é, desde o início orientado para um interesse parcial da categoria ou da classe ao invés do "interesse geral"), tal acordo tem uma virtualidade pública pela possibilidade de ser tentado; pelo menos, é legítimo que o seja. Esse é um aspecto importante porque significa que os atores não precisam remeter seus interesses de fato a um interesse geral sublimado, apenas para justificar a sua ação perante os outros membros da "cidade" (isso implica que essa última, enquanto "espaço cívico"11, possa ser complexa e diferenciada). Em suma, podem variar as profissões, as qualificações, a base econômica e tecnológica, mas a variabilidade das experiências coletivas de trabalho não afetaria a chance de uso da palavra, da atenção da outra parte (ser levado(a) em conta) e de uma decisão obrigatória dentro de um âmbito definido: sua validade no mínimo alcançaria o que se poderia designar como um "interesse geral

\footnotetext{
${ }^{11}$ Utiliza-se aqui a terminologia empregada por Pharo (1985).
} 
restrito". Mas a vocação à universalização - falar em nome de um ideal de bem comum - confere aos acordos uma tendência de ser válidos para todos e não apenas para o grupo original que os protagonizou.

Outro aspecto é que os argumentos levantados sempre têm como destinatário a coletividade concernida - aqui pode-se chamá-la metaforicamente de "cidade" - mesmo quando se referem a ações que se desenrolam fora da referida coletividade: a empresa, por exemplo, orienta o acordo - digamos, sobre produtividade - para uma realização distante fisicamente do locus abrangido pelo acordo (a unidade produtiva, ou a própria firma ou grupo econômico), a captura de parcelas do marcado externo, a concorrência com outras empresas, a qualidade do produto como passaporte para a competitividade etc.; todavia, os benefícios, bem como os sacrifícios são medidos internamente, na "comunidade", isto é, na empresa.

Em terceiro lugar está o fato de que, por remeter sempre a uma experiência coletiva do grupo que é sujeito do acordo visado, esse último lembra permanentemente os fundamentos que estão na base do "interesse geral" da coletividade. Ao agir, os sujeitos têm de justificar a sua ação e, com isso, reinterpretam aqueles fundamentos todo o tempo, contribuindo para consolidá-los. Se uma caída corporativa não deixa de estar descartada, o fato da publicidade funciona como contratendência, pois o outro envolvido no acordo pode também forçar a reflexão e a reconsideração interna dos próprios fundamentos do grupo. Como se fez referência anteriormente, o procedimento deliberativo transforma as preferências (as éticas particulares mas também a moral pública) e não as considera como "dadas" desde sempre.

De acordo com o princípio da publicidade, não basta apenas que os acordos sejam convincentes, isto é, baseados no melhor argumento; é preciso que todos possam ter acesso a eles e, o que é importante, possam também contradizê- 
los. Nessa altura, surge um dos obstáculos mais comuns nas decisões deliberativas, que é o das exigências técnicas. Quando elas surgem, o argumento aparece como objetivamente neutro e irretorquível diante dos cidadãos. A possibilidade do contraditório sofre uma limitação interna ao próprio discurso, o que acaba tendo um rebatimento na participação das decisões, pois os membros da coletividade podem enxergar todo o seu esforço de elaboração de propostas razoáveis no fim das contas inútil. Se é concedida uma imagem para descrever o efeito, pode-se dizer que o monopólio do saber detido por alguns grupos especializados, tanto do ponto de vista técnico quanto administrativo, exerce uma espécie de força gravitacional sobre a argumentação, torcendo-a de acordo com a massa de informação objetivante acumulada. Na prática, o que ocorre é que a justificação, como se viu acima, pode ser pública, mas a implementação em geral cabe aos experts. Tal fato funciona por si só como um poderoso argumento antideliberativo; contudo pode também aparecer mascarado por razões de cunho realista quando se invoca o fator tempo: como é sempre preciso que se decida sobre algo (não podendo o debate perdurar indefinidamente), então é mais seguro que uma elite o faça ${ }^{12}$.

Mesmo assim, a chance de "colocar as cartas na mesa", isto é, de estabelecer acordos deliberativos, como que empurra os argumentos técnicos sempre para a necessidade de sua justificação prática, normativa. Nisso consiste a eficácia (do ponto de vista dos membros da "cidade") da publicização dos acordos, especialmente no mundo do trabalho e de suas instituições. Quando a categoria patronal, numa negociação coletiva de qualquer natureza ${ }^{13}$, levantava os constrangimentos

\footnotetext{
${ }^{12}$ Está-se supondo aqui que a implementação é um momento também da deliberação porque supõe o acompanhamento público (e, portanto, o controle) da decisão. A introdução do fator tempo é lembrada por Jon Elster, "Introduction", 1998, pp. 1-18.

${ }^{13} \mathrm{Na}$ câmara setorial isso era muito comum, na medida em que não havia, por 
do tipo: volume de investimento necessário, preços de matérias-primas, peso da folha de salários na composição dos custos das firmas etc., tais argumentos podiam ser questionados por uma contra-força-tarefa intelectual (nos sindicatos mais bem preparados em termos de assessoria, isso de fato acontece) que no entanto discutia os argumentos dentro de um mesmo "campo" (econômico). Mas, além da oportunidade de a discussão levar a que se levantem outros pontos de vista dentro do mesmo campo argumentativo - ao invés da necessidade "férrea" de enxugar os quadros de funcionários por causa da competição internacional promovida pela entrada de produtos estrangeiros, por exemplo, por que não reorientar o mix de produtos com vistas ao mercado interno? etc. - ela também pode mudar a natureza do próprio argumento, por exemplo, introduzindo premissas não econômicas mas de justiça: por que é prioritário para as políticas públicas do Estado combater a inflação com o sacrifício da política industrial, ou relegar o ataque aos focos de pobreza e não promover o aumento da participação da renda do trabalho no conjunto da riqueza nacional? Nesse caso, não se trataria apenas de capacitar melhor a assessoria sindical e aproximá-la, em termos de competência, da assessoria empresarial - para isso seria suficiente acionar um dispositivo baseado em uma sorte de "princípio da diferença", a fim de mitigar os desníveis no ponto de partida. Na verdade, o acordo baseado na deliberação prevê a própria mudança do foco original da questão tratada, devido à incorporação do maior número de interessados e, por conseguinte, da consideração de novos pontosde-vista. Ensaios desse tipo, como se sabe, foram tentados no Brasil. Eles levariam a uma reação em cadeia que certamente interfeririam em outras lógicas de decisão que não se pautam por procedimentos deliberativos.

assim dizer, limite para a tematização de problemas, variando desde a realidade econômica das empresas até a política industrial do governo ou as tendências globais dos mercados. Veja-se por exemplo Mello e Silva (2002). 
Finalmente, a conseqüência das decisões saídas de acordos deliberativos é que eles devem ter a força de uma obrigação. Isso remete a um problema delicado que é a relação com o direito e, em última instância, com a "lei maior" (Constituição). O enquadramento sociológico em geral aborda esse problema como sendo de "legitimação". Inspirações teóricas diversas confrontam-se aqui em um ponto que é cheio de conseqüências práticas. Enquanto uma corrente fenomenológica encara os acordos como fruto de uma "razão prática" que se origina e ao mesmo tempo se esgota em uma situação socialmente determinada (o "interesse geral restrito"), não podendo ser generalizada como normatividade para outros contextos, uma outra corrente, que tem em Habermas ${ }^{14}$ seu expoente, procura fincar os acordos deliberativos em uma predisposição transcendental para a comunicação e o entendimento recíproco. A implicação está, em primeiro lugar, no estatuto do que poderíamos chamar de "contrato": a primeira corrente enfatiza muito mais a confiança como base do acordo - o contrato propriamente não é, em si, tão decisivo, não garante nada, a não ser a remissão ao "interesse geral" da coletividade -, enquanto a segunda corrente vê a norma como garantia e protetora do fático, sendo por isso o contrato muito importante. Ambas são, em certo sentido, procedimentalistas, porém a carga normativo-abstrata da segunda é adequada ao tipo de linguagem corrente da legitimação em sociedades modernas, isto é, o direito e a lei.

\section{Política deliberativa nas relações de trabalho?}

$\mathrm{Na}$ seção anterior a política deliberativa foi considerada quanto à sua aplicação no âmbito das relações industriais, isto é, nas relações entre sindicatos e associações patronais, Estado e, eventualmente, sociedade civil. Embora não

\footnotetext{
${ }^{14}$ Habermas $(2003,1997)$.
} 
sejam tratadas no texto de maneira sistemática e descritiva, as câmaras setoriais poderiam ser um bom exemplo, bem como as experiências mais recentes de concertação social e mesmo de "novo contrato social", de iniciativa do Governo Federal ${ }^{15}$. Faltaria considerar a possibilidade de aplicação de seus princípios no âmbito das relações de trabalho, isto é, na vida organizacional das empresas. Nesse que seria, por definição, um espaço privado, o procedimento deliberativo encontraria um obstáculo mais robusto, tendo em vista a ordem capitalista e sua separação legitimada formalmente de esferas de propriedade.

No entanto, como já se fez referência anteriormente, tais espaços legitimados formalmente são constantemente redefinidos. As esferas do público e do privado sofrem transformações, ganhando novas feições e significados: o Estado-Providência ou Estado de Bem-Estar Social, resultado de um modo de regulação monopolista após as crises dos anos 1930 e a $2^{\text {a }}$ Guerra, foi um desses momentos de viragem. Estamos talvez em um outro momento de viragem, derivado dos novos modelos produtivos que se espalham no tecido industrial: as empresas se vêem confrontadas com mudanças importantes na sua estrutura (geográfica, material, tecnológica e também "relacional" com sua força-detrabalho). Programas de qualidade, talvez inadvertidamente, abrem espaço para uma relação comunicativa no dia a dia da produção - com todos os constrangimentos ligados à racionalização tradicional que eles envolvem -, porque o medium da linguagem se infiltra sorrateiramente nos processos de trabalho, exigindo a substituição do signo que traduz a mera prescrição da operação por uma entente entre trabalhadores e supervisores sobre o como fazer $^{16}$. Com isso, o "tra-

\footnotetext{
${ }^{15}$ Um bom apanhado está em Véras (2004, pp. 45-73).

${ }^{16}$ Um autor como Philippe Zarifian foi um dos que desde cedo se mostrou sensível a esse tipo de implicações. Veja-se Zarifian (1996, e em português, do mesmo autor, 1991).
} 
balhador coletivo" fica confrontado a uma medida de tempo (a definição da jornada de trabalho) e do próprio dispêndio de força de trabalho (dependendo cada vez menos de uma intervenção particular ) que tendem a esgarçar as fronteiras antes muito rígidas do público e do privado, do "interior" e do "exterior", do que deve ser escondido e do que deve ser exibido. Se os temas relativos à "moral" - porque têm uma afetação pública - são o objeto da discussão e da decisão, enquanto as questões "éticas" não devem entrar em linha de conta, no universo do trabalho real essa divisão há muito vem sofrendo trepidações: disposições subjetivas (por exemplo, no modelo de gestão pelas competências) são exigidas na avaliação profissional do(a) trabalhador(a), gerando em seguida critérios objetivos de desempenho.

Por outro lado, os constrangimentos sociológicos entram com todo o seu peso na definição dos lugares em que os sujeitos emitem os juízos deliberativos. Esses lugares são identificados imediatamente pelos interlocutores e afetam a percepção dos juízos emitidos, contaminando o seu conteúdo racional. Um juízo emitido de um lugar simbolicamente subordinado na estrutura de poder discursivo tem um efeito completamente diferente de outro, identificado com recursos maiores e acúmulo de capital cultural. Um acordo em que estão presentes sindicalistas e empresários produz uma expectativa prévia nos agentes não só sobre os argumentos que vão ser mobilizados, de lado a lado, bem como sobre as margens em que eles podem ser sustentados, transgredidos e retrabalhados, a velocidade desse reprocessamento e outros aspectos. A classe conta. Assim como os signos corporais e os recursos expressivos associados a ela.

Exemplos podem ser encontrados nos relatos de entrevistas com os agentes participantes dos processos deliberativos postos em marcha no mundo do trabalho nos últimos anos. No caso da Câmara Setorial do Complexo Químico, 
transcorrida no Brasil entre 1993 e $1994^{17}$, o linguajar e a barba, do lado trabalhista, foram as marcas de classe lembradas pelos informantes. Ora, nesse último caso, estamos seguramente diante de um dos traços que estão associados à cultura sindical, em especial na representação disseminada de um sindicalismo "de briga", "aguerrido" etc.

Por fim, vale notar que a abertura para a consideração de diferenças sociais no interior de práticas deliberativas permite a inserção da variável de gênero, bem como de outras clivagens presentes na estrutura social que demonstram a necessidade de levar em conta a desigualdade que atravessa a "situação ideal de discurso". Uma advertência que poderia ser incorporada como uma questão de justiça, na medida em que o "princípio de diferença" considerasse os recursos simbólicos como parte constituinte das condições de ponto de partida ${ }^{18}$.

\section{Balanço}

Qual a relevância da discussão empreendida acima para o campo dos estudos do trabalho? E mais: qual a relevância para a pauta das relações de trabalho no momento em que se discute um desenho institucional para o novo Sistema Nacional de Relações de Trabalho no Brasil?

No primeiro caso, a sugestão é que a DD deve de alguma maneira inserir-se no temário das relações industriais porque há muito tempo suas premissas vêm freqüentando de maneira difusa a reflexão na área, de maneira não sistemática: índices, aqui e ali, de que estaríamos vivenciando traços de "ação comunicativa" nas indústrias modernas, de "nova contratualidade" nas negociações sindicais, de consensos pactados, de uma relação de serviços que dilui

\footnotetext{
${ }^{17}$ Para uma apreciação ampla da câmara setorial do complexo químico, consultese Mello e Silva (2002).

${ }^{18}$ Uma observação desse tipo aparece em Young (2001).
} 
a materialidade da prestação do trabalho direto, são todas indicações que desafiam o marco político, entendido esse último como regulação da "cidade", do espaço cívico. O formato da DD pode ser, em tese, um marco político adequado para os problemas colocados pelo "subsistema" econômico e das relações de trabalho que lhe são derivadas. No entanto, forças poderosas, vindas desse mesmo "subsistema" (globalização, acirramento da concorrência, instabilidade dos modelos produtivos em função da sua dependência ao capital financeiro especulativo etc.) podem apontar exatamente o contrário: a dificuldade de regulação política, ou a redução do tipo de dificuldades que estão envolvidas (velocidade das informações, tecnociência, escala de implicações etc.) a uma solução de tipo decisionista. O que, aliás, não deixa de ser também uma política: decisão sem discussão.

No segundo caso, a inspiração é mais evidente e os exemplos dos últimos anos (alguns mencionados no texto) parecem reforçar a idéia de que caminhamos para um padrão "compreensivo" de relações de trabalho, com a incorporação dos sindicatos como atores coletivos públicos (participação em fora de concertação social e de gestão de fundos estatais). Se assim é, os mesmos dilemas e perguntas apontados no parágrafo anterior poderiam ser endereçados aqui. Fica a questão: até que ponto aquela incorporação significa de fato uma publicização da política, com a inclusão de mais e mais participantes racionalmente competentes e igualmente capazes de imprimir uma dinâmica societária, não apenas circunscrita ao trabalho, plural e estável?

De um ponto de vista mais específico - e à guisa de conclusão - a pertinência da abordagem da DD para o trabalho tem de enfrentar as objeções mais prováveis. Primeiro, no fundo, de que seus requisitos não passam de um grande truísmo. Participação, igualdade, racionalidade dos agentes, publicidade são todos princípios inquestionáveis hoje e, portanto, com esse grau de generalidade não esclarecem muita 
coisa. Segundo, de que valeriam para toda e qualquer ação coletiva e não apenas para a ação sindical e outras, referidas ao mundo do trabalho. Terceiro, de que o aporte da DD não acrescenta nada de novo e apenas confirma o que já se sabe, até mesmo intuitivamente, acerca da necessidade de legitimação das ações coletivas ou da democratização das relações de trabalho (derivada dos requisitos de participação e igualdade). À pergunta de qual a sua contribuição original para as relações de trabalho, pode-se dizer que o que é promissor na abordagem da DD é que a exigência de justificação das decisões descerra a possibilidade de "abrir a caixa preta" relativamente a decisões estratégicas das firmas e do Estado (os dois "subsistemas" teoricamente infensos à sua influência). Por fim, a objeção quanto ao requisitos ou princípios de publicidade e racionalidade (que todas as partes sejam capazes de apresentar seus interesses e defendê-los sob a ótica da universalização dos resultados), o qual esbarraria em fenômenos conhecidos de encerramento corporativista da classe. Quanto a esse ponto, uma discussão foi empreendida no texto no sentido de mostrar que o "interesse geral" está sempre pressuposto nas ações que visam a um interesse particular, de grupo. Os agentes remetem sempre a um "todos" quando querem se referir a uma situação desejada para si mesmos. Se uma tal remissão está associada a uma disposição "transcendental" imanente à "razão comunicativa" ou, antes, a uma disposição "ordinária" da vida social, só uma pesquisa que persiga essas questões - o que é, de resto, válido para o conjunto das objeções levantadas acima - vai poder responder. Esse seria um próximo passo.

\section{Leonardo Mello e Silva}

é professor do Departamento de Sociologia da Faculdade de Filosofia, Letras e Ciências Humanas da USP 


\section{Referências bibliográficas}

ARENDT, H. 1991. A condição humana. $5^{\mathrm{a}}$ ed. Rio de Janeiro: Forense.

CASTEL, R. 1995. Les métamorphoses de la question sociale. Une chronique du salariat. Paris: Fayard.

ELSTER, J. (ed.). 1998. Deliberative democracy. Cambridge: Cambridge University Press.

HABERMAS, J. 1997. Direito e democracia. Rio de Janeiro: Tempo Brasileiro. vol. II.

leiro. vol. I.

2003. Direito e democracia. $2^{\text {a }}$ ed. Rio de Janeiro: Tempo Brasi-

MELLO E SILVA, L. 2002. "Novas formas de ação sindical. As câmaras setoriais e a câmara setorial do complexo químico”. In: FONTES, P. (org.). A química da cidadania. São Paulo: Viramundo.

OLIVEIRA, F. de et al. 1993. "O acordo das montadoras: quanto melhor, melhor”. Novos Estudos Cebrap, São Paulo, no 36.

PHARO, P. 1985. Le civisme ordinaire. Paris: Méridiens.

PIORE, M. J. 1995. Beyond individualism. Cambridge and London: Harvard University Press.

VÉRAS, R. 2004. "Governo Lula, pacto social e acção sindical”. In: ESTAN-

QUE, E. et al. (orgs.). Relações laborais e sindicalismo em mudança. Portugal, Brasil e o contexto transnacional. Coimbra: Quarteto.

WOMACK, J.; JONES, D.; ROOS, D. 1990. The machine that changed the world. MIT Press.

YOUNG, I. M. 2001. "Comunicação e o outro: além da democracia deliberativa”. In: SOUZA, J. (org.). Democracia hoje. Novos desafios para a teoria democrática contemporânea. Brasília: Editora UnB.

ZARIFIAN, P. 1996. Travail et comunnication. Paris: PUF.

1991. "Trabalho e comunicação nas indústrias automatizadas".

Tempo Social, São Paulo, vol. 3, nº 1-2, pp. 119-130. 
desdobramentos públicos das lutas de um movimento, com base na noção de esfera pública. Discorre-se, por fim, sobre o freqüente processo de engessamento dessa agência coletiva na burocratização de uma entidade que se quer unificada.

Palavras-chave: Acontecimento; Movimentos sociais; Esfera pública.

\section{SOCIAL MOVEMENTS AS EVENTS: LANGUAGE AND PUBLIC SPACE}

This paper makes use of the concept of "event" in order to reflect on the processes through which social movements act and constitute themselves. The idea is to analyze the displacing potential that can be engendered by these collective agencies, which give life to participative practices that are essential to democracy. The discussion begins with a brief presentation of the concept of event, focusing especially on the ideas of Louis Quéré. In the sequence, it establishes some connections between the concept of "event" and social movements, highlighting the importance in this context of Arendt's notions of "action" and "new beginning". At this point the paper evidences that the public unfolding of a social movement struggle can be thought of as an "event", if one has in mind the meaning of such concept. Finally, it discusses the recurrent process of crystallization of these collective agencies by means of their unification in a bureaucratized entity.

Keywords: Event; Social movements; Public sphere.

\section{É POSSÍVEL UMA POLÍTICA DELIBERATIVA PARA 0 TRABALHO?}

\section{LEONARDO MELLO E SILVA}

As relações trabalhistas vêm apresentando uma série de iniciativas de negociação inovadoras nos últimos anos no Brasil, seja no âmbito da concertação social, seja no âmbito 
das relações de trabalho dentro das fábricas, que apontam para a mobilização de uma postura dialógica e compreensiva entre os interlocutores ou atores coletivos. Os limites de uma tal postura em uma situação de conflito de classe estão para ser estabelecidos. $\mathrm{O}$ artigo procura incorporar a discussão teórica sobre a democracia deliberativa para aquele tipo de situação, a fim de testar a sua pertinência. A ênfase recai na observação das precondições teóricas quanto à arbitragem dos conflitos em situações determinadas, extraídas de pesquisa prévia do autor. A hipótese subjacente é de que o procedimento deliberativo no trabalho pode estar a indicar um alargamento da esfera pública no Brasil.

Palavras-chave: Democracia deliberativa; Relações industriais; Contratação coletiva.

\section{IS IT POSSIBLE A DELIBERATIVE POLITICS IN LABOR?}

204 Industrial relations in Brazil have been presenting nowadays a series of innovative negotiations coming from the initiative of collective actors themselves either on the macro social concertation level as well as on labor relations at the plant micro level. These initiatives point to the incorporation and use of a dialogic and comprehensive approach between interlocutors based on the deliberative democracy's analytical body. The limits of such approach in the classical class conflict situations are still to be theoretically stood. This paper aims to make use of that intellectual and academic tool in order to understand practical situations and then testing the accuracy of the tentative use of that tool itself to specific and concrete topics of sociological research. Underlying the paper is the idea that the deliberative procedure on the work's world is a way to enlarge public sphere in Brazil.

Keywords: Deliberative democracy; Industrial and labor relations; Collective bargaining. 